\title{
Fusion Strategy of Influenza A-H5N1 Virus M2e Epitope DNA Sequence to Hepatitis B Virus HBsAg-S Gene
}

\author{
Afifatul Achyar ${ }^{1}$ Tati Kristianti ${ }^{2}$ Sony Suhandono ${ }^{2 *}$
}

\author{
${ }^{1}$ Biology Department, Math and Natural Science Faculty, Universitas Negeri Padang, Padang, Indonesia \\ ${ }^{2}$ School of Life Science and Technology, Bandung Institute of Technology, Bandung, Indonesia \\ *Corresponding author.Email: sony@sith.itb.ac.id
}

\begin{abstract}
In order to make a broad vaccine for influenza-A virus, a conserve epitope must be considered. M2 is a conserve transmembran protein in all strain of influenza-A virus. Therefore, in this experiment we used 69 bp synthetic nucleotides from extracellular domain of M2 from H5N1 as an epitope (M2e) for influenza-A vaccine. A vaccine may usually more expose to immune system if they are made on a virus-like particles (VLPs). It was shown in many papers that the HBsAg-S protein is able to make a self assemble VLP. Therefore the synthetic M2e DNA was fused to a HBsAg-S gene, which encodes a small envelope protein of the Hepatitis B virus (HBsAg-S protein), which in turn creating a new VLP with M2e on it. This fusion replaced IPQ epitope of the HBsAg-S with M2e from M2 protein of the $\mathrm{H} 5 \mathrm{~N} 1$ virus. The fusion of M2e and $\mathrm{HBsAg}-\mathrm{S}$ was conducted using asymmetric PCR. The single stranded DNA of M2e was produced with primers containing HBsAg-S gene sequence. Next, this single-stranded M2e was applied as mega primer for 'fusion PCR', which will fuse the M2e and part of the HBsAg-S fragment. A 680 bp DNA band (fusion of M2e and HBsAg-S fragment) is generated from the 'fusion PCR'. Alignment between hypothetic fusion sequence and the result was compared with native $\mathrm{HBsAg}-\mathrm{S}$ sequence. The analysis shows that the IPQ epitope from $\mathrm{HBsAg-S}$ was totally replaced by the M2e..
\end{abstract}

KeyWord: A-H5N1 VLPS vaccine, asymmetric PCR, HBsAg-S, M2.

\section{INTRODUCTION}

Influenza-A vaccine should have an epitope, which is conserved for all influenza-A virus strains to get a broad spectrum and efficacious vaccine [1]. Commercial influenza vaccines generally include surface protein HA (hemagglutinin) and NA (neuraminidase), which has 16 and 9 known subtypes respectively, as major antigen protein. However, a constant antigenic reassortment in $\mathrm{HA}$ and NA makes vaccine development a complicated process. As a consequence, influenza vaccines are produced each year after comprehensive global surveillance, analyzing and prediction of the main circulating strains [2]. These reformulated versions of influenza vaccines are applicable for a short time and only protective when the HA of the vaccine strain is well-suited to the HA of the circulating virus [3].

In addition to HA and NA, there is another integral membrane protein in influenza A virus, that is matrix 2 protein (M2). M2 is only 97 amino acids long, smaller than HA and NA. This protein has three domains, those are extracellular domain (24 amino acid), plasma membrane-spanned domain (19 amino acids), and cytoplasmic domain (54 amino acids) [4]. The extracellular domain of the M2 protein (M2e) is highly conserved across all influenza A isolates, so that M2e can be a good epitope target for influenza A vaccine development [1].

In order to increase vaccine safety and overcome the limitation in vaccine supply from conventional egg-based manufacturing system, it is important to develop alternative influenza vaccines [5]. Virus-like particles (VLPs) as an alternative vaccine, may provide an ideal combination of efficacy and safety [6]. Principally, VLP is a recombinant vaccine in which the immunogenic particle resembling a virus, but it does not have virus genetic material. Therefore, VLP is not infectious.

The Hepatitis-B and human papiloma virus (HPV) vaccines are the first VLPs based vaccines approved by the US, Food and Drug Administration (FDA). Small envelope Hepatitis B virus surface antigen (HBsAg-S) is able to assemble into highly organized VLPs. In addition, HBsAg-S can be used as vector to deliver foreign epitope [7].

Based on those facts, we fused synthetic M2e sequence from Influenza A-H5N1 virus to Hepatitis B Virus HBsAg-S sequence with the purpose to develop A-H5N1 virus-like particles based vaccine. In this article, we demonstrate a strategy to fuse M2e and HBsAg-S sequence with PCR based technique, including asymmetric PCR

\section{MATERIALS AND METHODS}

\section{Synthetic M2e H5N1}

The M2e sequence was adopted from Nemchinov \& Natilla [2]. The synthetic M2e was designed with some modifications. The first modification was made by including a few base pair from HBsAg$\mathrm{S}$ sequence which flanked the M2e sequence. The second modification was made on synthetic fragment is changes in several nucleotide sequence in order to escape from cryptic intron signal. This synthetic DNA fragment was ordered to DNA 2.0, Inc (Menlo Park, CA). 
The synthetic sequence was:

tcttgttgacaaaaatcctcacaTCACTTCTTACTGAAGTGGAAACT CCTACTAGAAATGAATGGGAATGㅡAGATGTTCEGATTCT TCTGATaattttctchggggaacaccotgtgtcttggccaaaa (uppercase: M2e $\mathrm{H} 5 \mathrm{~N} 1$; lowercase: $\mathrm{HBsAg}-\mathrm{S}$; bold and underline: modified to escape cryptic intron).

\section{Preliminary PCR}

Preliminary PCR was aimed to generate only double stranded M2e-H5N1 sequence (144 bp) from synthetic gene PJ201 plasmid (DNA 2.0). This PCR used M2e-F (5'-ACA GGC GGG GTT TTT CTT GTT GAC-3') as forward primer and M2e-R (5'-ATT TTG GCC AAG ACA CAC GC-3') as reverse primer. The product of preliminary PCR was purified and then used as template for asymmetric PCR.

\section{Asymmetric PCR}

Asymmetric PCR is optimize PCR using asymmetric primer (high concentration primer and low concentration primer), so that the major product is single stranded DNA. Concentration ratio for excess and limiting primer was 50:1. Primer of asymmetric PCR was designed for different concentration in order to achieve highest reaction efficiency and specificity. Melting temperature (Tm) of limiting primer should be higher than Tm of excess primer [8]. $\mathrm{M} 2 \mathrm{e}-\mathrm{F}$ primer was used as limiting primer $(\mathrm{TmL}=64.6 \mathrm{oC})$ and M2e-R was used as excess primer $(\operatorname{TmX}=60.4 \mathrm{oC})$.

DNA template for this PCR was purified preliminary PCR product (double stranded $144 \mathrm{bp} \mathrm{M2e).} \mathrm{PCR} \mathrm{samples} \mathrm{included} 50$ $\mu \mathrm{M}$ excess primer (M2e-R), $1 \mu \mathrm{M}$ limiting primer (M2e-F), $50 \mu \mathrm{M}$ dNTPs, 0.5 unit/ $\mu$ l DreamTaq (Fermentas), 1X PCR buffer (1.5 $\mathrm{mM} \mathrm{MgCl} 2,50 \mathrm{mM} \mathrm{KCl}, 20 \mathrm{mM}$ Tris- $\mathrm{Cl} \mathrm{pH} 8.5$, and $0.1 \%$ Tween 20).

The first denaturing step of 1 minute at $950 \mathrm{C}$ was followed by 25 cycles of $950 \mathrm{C}$ for 30 seconds, $58.40 \mathrm{C}$ for 30 seconds (annealing), and $72 \mathrm{oC}$ for 30 seconds (elongation), then final elongation was conducted at $72 \mathrm{oC}$ for 7 minutes. According to Pierce [8] annealing temperature for asymmetric PCR was conducted $2 \mathrm{oC}$ below $\mathrm{TmX}(58.4 \mathrm{oC})$. The product of asymmetric PCR, which mostly was single stranded 144 bp M2e, was purified and then used as mega primer for fusion PCR.

\section{Fusion PCR of M2e and HBsAg-S}

DNA template for fusion PCR was plasmid containing HBsAgS. PCR samples included $0.5 \mu \mathrm{l}$ purified M2e mega primer as forward primer, $0.5 \mu \mathrm{M}$ HBsAg_rev (5'-ACC GGT CAC CTT AAA TG-3'; $\mathrm{T}_{\mathrm{m}}=61.9^{\circ} \mathrm{C}$ ) as reverse primer, $0.2 \mathrm{mM}$ dNTPs, 0.5 unit/ $\mu$ l DreamTaq (Fermentas), 1X PCR buffer (1.5 mM MgCl 2 , $50 \mathrm{mM} \mathrm{KCl}, 20 \mathrm{mM}$ Tris-Cl pH 8.5, and 0.1\% Tween 20).

An initial denaturation step of 3 minute at $95^{\circ} \mathrm{C}$ was followed by 25 cycles of $95^{\circ} \mathrm{C}$ for 30 seconds, $60^{\circ} \mathrm{C}$ for 30 seconds (annealing), and $72^{\circ} \mathrm{C}$ for 1 minute (elongation), then final elongation was conducted at $72^{\circ} \mathrm{C}$ for 7 minutes.

Cloning of fused M2e-HBsAg in E.coli

Product of fusion PCR (680 bp) was purified and then ligated to pGEM-T easy vector (Promega corporation, USA) and cloned in Escherichia coli top 10. Plasmid from white colony E.coli was isolated using alkaline-lysis method and cut with EcoRI enzyme to confirm the insert (fused M2e-HBsAg). The plasmid containing fused M2e-HBsAg was sequenced at Macrogen, Inc (South Korea).

\section{RESULT AND DISCUSTION}

Because this gene will be transiently expressed in plant, we altered several nucleotides in order to remove the cryptic intron signal. The cryptic intron is defined as a region of a coding sequence that is false recognized as an intron, which will be cut out from the primary mRNA transcript [9]. Cryptic intron consensus sequence is divided to 5'cryptic consensus sequence (GT, GC, CT, GTANGT, GCANGT, or CTANGT), branchpoint with high AT content (CTNAN), and 3'cryptic consensus sequence (AG, CAG, TAG, or AAG) [9, 10]. Based on this consensus, we altered the nucleotide at 71 position $(\mathrm{T} \rightarrow \mathrm{C}), 80$ position $(\mathrm{T} \rightarrow \mathrm{C})$ and 101 position $(\mathrm{A} \rightarrow \mathrm{C})$ in M2e synthetic gene to remove the cryptic intron.

\section{Preliminary PCR}

Preliminary PCR product was run in $2 \%$ agarose gel in order to separate 144 bp M2e H5N1 fragments (Figure 1). The $144 \mathrm{bp}$ fragment was purified using Gel Extraction Kit (Geneaid Biotech Ltd.) and then used as template for asymmetric PCR.

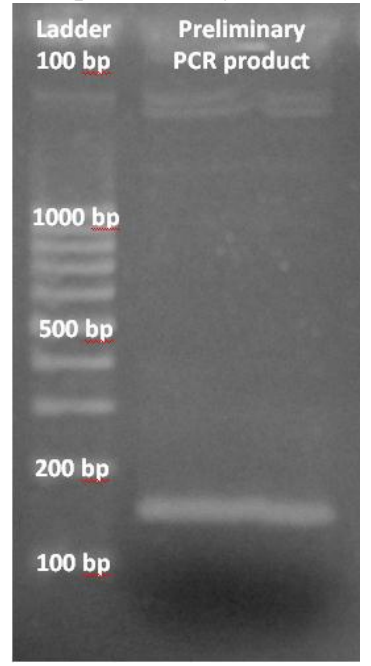

Figure 1. Electrophoresis result of preliminary PCR product (144 bp).

Asymmetric PCR

The major product of asymmetric PCR was single stranded DNA. Approximately 144 bp DNA fragment was separated in $2 \%$ agarose gel (Figure 2). This fragment was supposed to be mostly single stranded M2e. M2e fragment was purified then used as a mega primer for fusion PCR.

The principal of asymmetric PCR is unequal concentration of primers, resulting single stranded DNA. When concentration of one primer is lower than the other, the melting temperature $\left(\mathrm{T}_{\mathrm{m}}\right)$ of that primer will decrease below the reaction annealing temperature and affect PCR efficiency [11]. Therefore, designing the primer for asymmetric PCR is a little bit different compare to conventional PCR. Thus, the melting temperature for limiting primer has to be designed higher than melting temperature of the excess primer. 


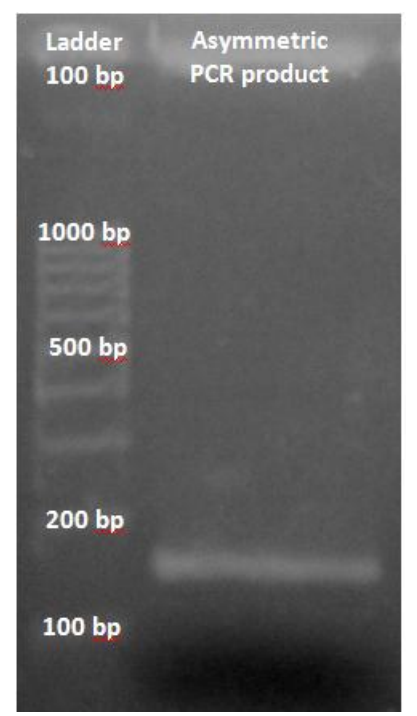

Figure 2. Electrophoresis result of asymmetric PCR product (144 bp).

Pierce [8] suggested that melting temperature $\left(\mathrm{T}_{\mathrm{m}}\right)$ of limiting primer should be at least $5^{\circ} \mathrm{C}$ higher than $\mathrm{T}_{\mathrm{m}}$ of excess primer. Although the $\mathrm{T}_{\mathrm{m}}$ difference between limiting primer (M2e-F: $64.6^{\circ} \mathrm{C}$ ) and excess primer $\left(\mathrm{M} 2 \mathrm{e}-\mathrm{R}\right.$ : $60.4^{\circ} \mathrm{C}$ ) only $4.2^{\circ} \mathrm{C}$, the asymmetric PCR reaction was accomplished, which was proved by the next fusion PCR of M2e to HBsAg-S using M2e mega primer resulted from asymmetric PCR.

\section{Fusion PCR of M2e and HBsAg-S}

If M2e successfully fused to $\mathrm{HBsAg-S}, 680$ bp DNA fragment will appear on the $1 \%$ agarose gel after electrophoresis. Electrophoresis result on Figure 3 shows the DNA band below $750 \mathrm{bp}$, this band was assumed as fused M2e and HBsAg-S (red circle). There were two other bands at $6000 \mathrm{bp}$ and $10.000 \mathrm{bp}$, those bands were remainder of HBsAg-S template. Fragment of fused M2e_HBsAg-S was purified and ligated to pGEM-T easy vector using 3:1 ratio, incubated at $4^{\circ} \mathrm{C}$ overnight. The clone was then transformed into Top 10 E. coli strain.

M2e sequence that brought by mega primer was successfully fused with $\mathrm{HBsAg-S}$ sequence. Using this strategy, we assume that one of HBsAg-specific cytotoxic T-lymphocyte (CTL) epitope, IPQ epitope (82-117 bp), were replaced by M2e epitope from H5N1. Replacing one of HBsAg-specific CTL epitope with foreign epitope will maintain the spatial requirement for VLP formation, the conformation of HBsAg molecule, and the antigen processing [7].

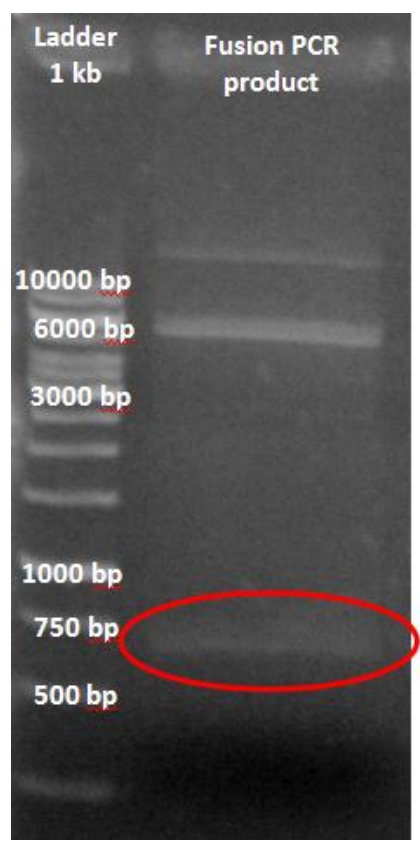

Figure 3. Electrophoresis result of fusion PCR product (680 bp).

Insert confirmation with EcoRI

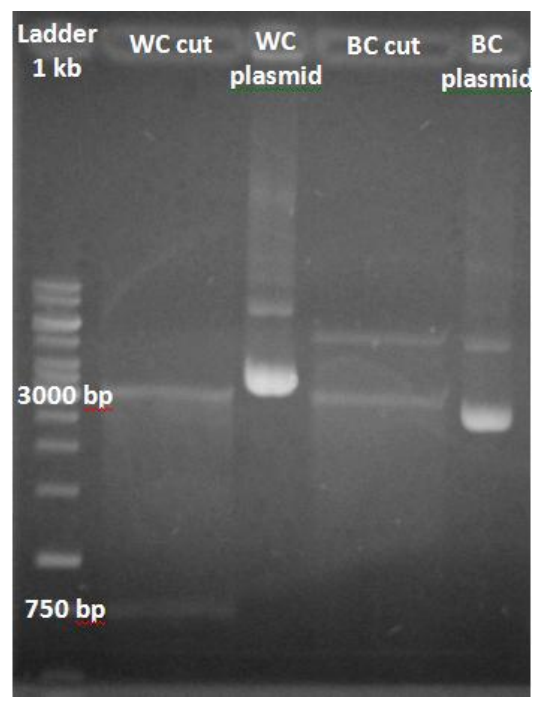

Figure 4. Electrophoresis result of insert confirmation with EcoRI. $W C$ cut: plasmid from white colony, digested with EcoRI; WC plasmid: plasmid from white colony, uncut; $B C$ cut: plasmid from blue colony, digested with EcoRI; $B C$ plasmid: plasmid from blue colony, uncut.

Isolated recombinant plasmids from E.coli were digested with endonuclease restriction enzyme $E c o R I$ at $37^{\circ} \mathrm{C}$ overnight. This enzyme will separate the insert from pGEM-T easy, so that 680 bp (insert=fused M2e_HBsAg-S) and 3000 bp (backbone from pGEM-T easy) bands appeared on $1 \%$ agarose gel (Figure 4). As negative control, plasmid from blue colony was also isolated and digested with EcoRI. This plasmid contained no insert, so that there was no $680 \mathrm{bp}$ on the agarose gel.

\section{Sequencing of fused M2e_HBsAg-S}

Sequencing result of fused M2e_HBsAg-S was aligned to native $\mathrm{HBsAg}-\mathrm{S}$ and hypothetical sequence of fused M2e_HBsAg-S (Figure 5). Native HBsAg-S has three cytotoxic T-lymphocyte (CTL) epitope, those are FLL epitope (58-84 bp), 
IPQ epitope (82-117 bp), and GLL epitope (586-615 bp). The sequence alignment shows that IPQ epitope was successfully replaced by $\mathrm{M} 2 \mathrm{e} \mathrm{H} 5 \mathrm{~N} 1$ sequence $(82-150$ bp). Almost all sequence of the sequencing result (M2e-HBsAg) is similar with the hypothetical sequence ( $\mathrm{H}-\mathrm{M} 2 \mathrm{e}-\mathrm{HBsAg})$, there is only one base difference between those at 675 bp position (A and $G$ ), this might be due to mismatch by DNA polymerase during fusion PCR. However the base changes was not changing the amino acid sequence (silence mutation) nor creating cryptic intron. Both codon CCG (native HBsAg-S) and CCA (fused M2e_HBsAg-S) will be translated to proline. These indicate that fusion strategy using asymmetric and fusion PCR was effective and efficient to fuse M2e-H5N1 and HBsAg-S.

At sequence number 159, there is one base difference between the sequencing result and native $\mathrm{HBsAg}-\mathrm{S}$ (C and $\mathrm{A}$ ). This dissimilarity was purposely conducted to increase codon usage at plant expression system (removing the cryptic intron).

Since IPQ epitope is at $82-117 \mathrm{bp}$, we could not design the M2e mega primer reached the first nucleotide (start codon) of HBsAg-S because it too large for a mega primer. The fused M2e_HBsAg-S that we have now is from $45^{\text {th }}$ nucleotide until HBsAg-S stop codon. Therefore, the fused M2e_HBsAg-S will be moved to complete sequence HBsAg-S using 'digest-ligate' strategy.

Previously, we had difficulty using 'digest-ligate' strategy because the insert (M2e) were placed in low copy number plasmid and should be digested with two different restriction enzymes (double digest). In order to bridge over this condition, we cloned the fused M2e_HBsAg-S in E. coli using pGEM-T easy vector (high copy plasmid). Insertion of fused M2e_HBsAg$\mathrm{S}$ to pGEM-T easy vector was confirmed by digestion with EcoRI (Figure 4) 


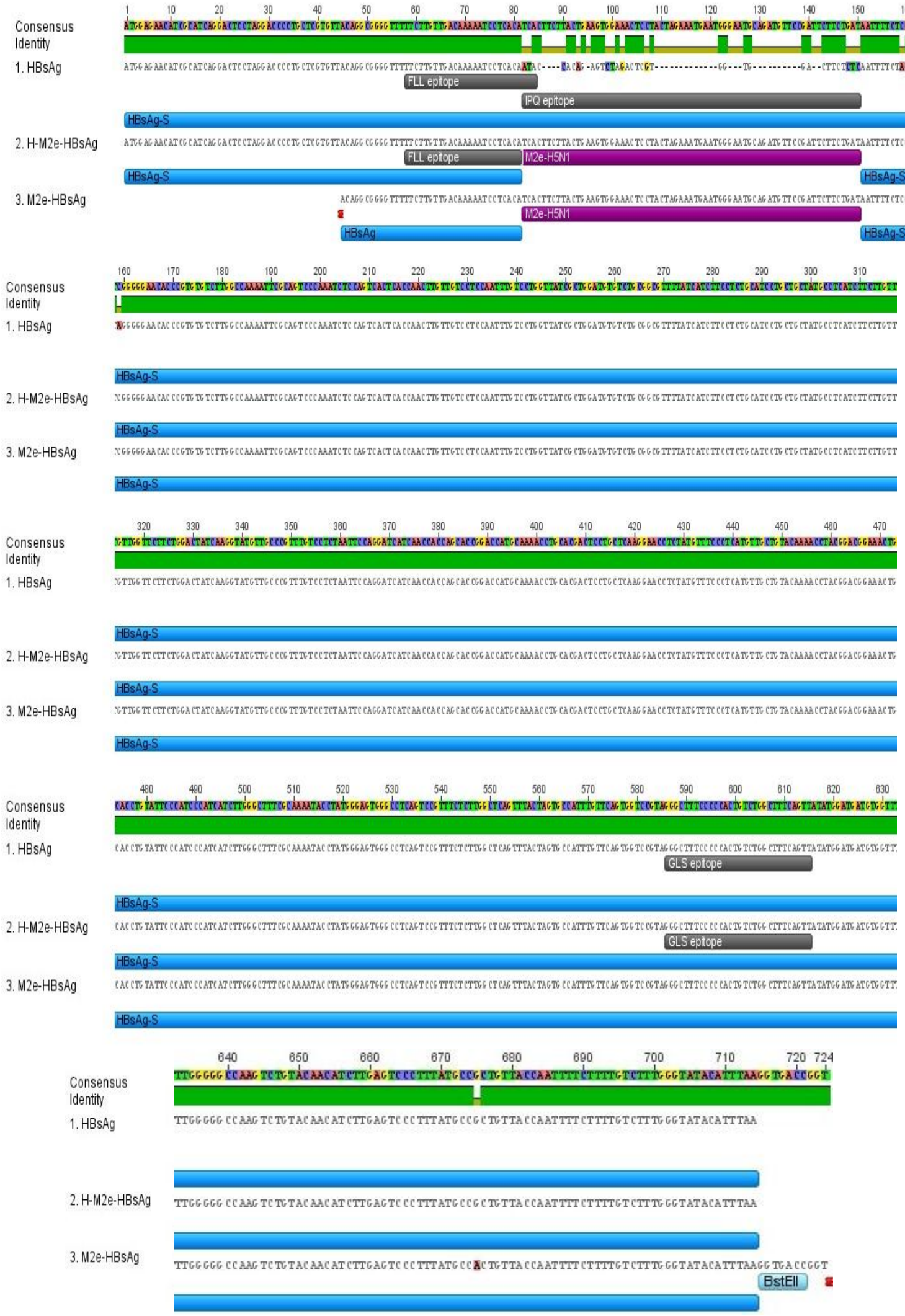

Figure 5. Sequences alignment of (1) HBsAg (native HBsAg-S); (2) H-M2e-HBsAg (hypothetical sequence of fused M2e_HBsAg-S); (3) M2e-HBsAg (sequencing result of fused M2e_HBsAg-S) 


\section{CONCLUSION}

Fusion of synthetic M2e-H5N1 to HBsAg-S sequence was successfully conducted using strategy based on PCR technique, including asymmetric PCR.

\section{REFERENCES}

[1] Denis, J., et al., Development of a universal influenza A vaccine based on the M2e peptide fused to the papaya mosaic virus (PapMV) vaccine platform, Vaccine, 26, 3395-3403, 2008.

[2] Nemchinov, L. G. \& Natilla, A., Transient expression of the ectodomain of matrix protein 2 (M2e) of avian influenza A virus in plants, Protein Expression and Purification, 56, 153-159, 2007.

[3] McMurry, J. A., Johansson, B. E. \& De Groot, A. S., A call to cellular and humoral arms, Human Vaccines, 4(2), 148157,2008

[4] Neirynck, S., et al., A universal influenza A vaccine based on the extracellular domain of the M2 protein, Nature Medicine, 5(10), 1157-1163, 1999.

[5] Kang, S. M., et al., Influenza vaccines based on virus-like particles, Virus Research, 143, 140-146, 2009.

[6] D'Aoust, M. A., et al., Influenza virus-like particles produced by transient expression in Nicotiana benthamiana induce a protective immune response against a lethal viral challenge in mice, Plant Biotechnology, 6, 930-940, 2008.

[7] Woo, W. P., et al., Hepatitis B surface antigen vector delivers protective cytotoxic T-lymphocite responses to diseaserelevant foreign epitopes, Journal of Virology, 80(8), 3975-3984, 2006.

[8] Pierce, K., et al., Linear-After-The-Exponential (LATE)PCR: Primer design criteria for high yields of specific singlestranded DNA and improved real-time detection, PNAS, 102(24), 8609-8614, 2005.

[9] Thompson, S. \& Calif, D., Modification of cryptic splice sites in heterologous genes expressed in fungi, U.S. Patent, 5770371, 1-11, 1998.

[10] Haseloff, J., et al., Removal of a cryptic intron and subcellular localization of green fluorescent protein are required to mark transgenic Arabidopsis plants brightly, Proc. Natl. Acad. Sci. USA, 94, 2122-2127, 1997.

[11] Sanchez, J. A., et al., Linear-After-The-Exponential (LATE)-PCR: An advanced method of asymmetric PCR and its uses in quantitative real-time analysis, PNAS, 101(7), 1933-1938, 2004. 